\title{
O USO DA EPISIOTOMIA NO SISTEMA ÚNICO DE SAÚDE BRASILEIRO: A PERCEPÇÃO DAS PARTURIENTES
}

\section{Camylla Aparecida Garrett}

Discente de Enfermagem no Centro Universitário Campos de Andrade (UNIANDRADE), Curitiba (PR), Brasil.

\section{Gleidson Brandão Oselame}

Mestre em Engenharia Biomédica pela Universidade Tecnológica Federal do Paraná (UTFPR); Discente do Programa de Pós Graduação em Engenharia Biomédica (PPGEB), Curitiba (PR), Brasil.

E-mail: goselame@ics.curitiba.pr.gov.br

\section{Eduardo Borba Neves}

Pós-Doutorado pela Universidade de Tras-os-Montes e Alto Douro, UTAD, Portugal; Docente no Programa de Pós-Graduação em Engenharia Biomédica (PPGEB), Curitiba (PR), Brasil.

\begin{abstract}
RESUMO: Este estudo teve como objetivo mapear as percepções das parturientes em relação à episiotomia sofrida com, ou sem, seu conhecimento e consentimento e suas consequências no pósparto. Tratou-se de uma pesquisa do tipo descritiva qualitativa com 50 parturientes. Em 76,27\% $(n=45)$ foram submetidas à episotomia sem o consentimento ou conhecimento prévio. Emergiram durante a entrevista fatores como grau de conhecimento e de orientação antecipada sobre o procedimento; possíveis complicações e cuidados após o parto; reação emocional e equipe de saúde frente a tal situação. As parturientes que só realizaram partos normais em todas as gestações predominaram com 52\% $(n=26)$ com faixa etária de 18 a 25 anos. Observou-se uma notória insatisfação das entrevistadas enquanto pacientes. As falas sugerem que a realização da episiotomia representou uma violação dos direitos sexuais, reprodutivos e emocionais das mesmas.
\end{abstract}

PALAVRAS-CHAVE: Episiotomia; Gestantes; Sistema Único de Saúde; Parto humanizado; Humanização da Assistência.

\section{EPISIOTOMY IN BRAZILIAN HEALTH SYSTEM: PREGNANT WOMEN'S PERCEPTION}

\begin{abstract}
Pregnant women's perception with regard to episiotomy, with or without consent, and its consequences in post-birth period is analyzed by a descriptive and qualitative research with 50 pregnant females. Further, $76.27 \%(n=45)$ of females underwent episiotomy without consent or previous consent. Interview revealed knowledge depth and anticipated directions on the procedure; possible complications and after-birth care; emotional reactions and health team in the process. Pregnant females with normal births predominated by $52 \%(n=26)$, within the $18-25$ years bracket. There was a great dissatisfaction of the interviewees: patients labeled episiotomy as a violation of sexual, reproduction and emotional rights.
\end{abstract}

KEY WORDS: Episiotomy; Pregnant women ; Unified Health System; Humanizing Delivery; Humanization of Assistance.

\section{INTRODUÇÃO}

A episiotomia é um processo cirúrgico no qual é executada uma incisão no períneo da mulher, no segundo período do parto, ou seja, momento da expulsão do feto. A palavra deriva do termo Epision que significa região pubiana. Esta técnica pode ser realizada com dois 
instrumentos cirúrgicos, a tesoura ou o bisturi. Após a episiotomia, procede-se a sutura local, denominada de episiorrafia (TORTORA; DERRICKSON, 2012).

Em algumas mulheres no processo de parto pode ocorrer trauma perineal, sejam pelas lacerações perineais espontâneas ou pela episiotomia (OMS, 1996). Quando acontecem lacerações que afetam pele e mucosa da vagina, são consideradas lacerações espontâneas, classificadas como de primeiro grau. As lacerações que chegam a atingir os músculos perineais, tornam-se lacerações de segundo grau. Já as que atingem o músculo esfíncter do ânus são as de terceiro grau. A episiotomia não só atinge a pele e mucosa, como secciona os músculos transverso superficial do períneo e o bulbocavernoso (TOMASSO et al., 2002; DINIZ; CHACHAM, 2006).

O corte da episiotomia foi criado por Felding Ould em 1742 (século XVIII). Ould servia em um hospital na Irlanda, como "Second Master" (Segundo Mestre). Para ele a incisão da episiotomia só deveria acontecer se fosse extremamente necessária, em caso de dificuldades nos partos (TOMASSO et al., 2002).

No entanto, este procedimento começou a ser entendido como um processo rotineiro, no início do século XX, depois que Joseph DeLee recomendou a todas as primíparas o uso da episiotomia e do fórceps de alívio em seu tratado intitulado "The Prophylactie Forceps Operation". DeLee alegava que a mulher sofreria menos danos e esforços no parto, que sua musculatura pélvica seria preservada, que o cérebro do bebê não sofreria pressões causadas pelo assoalho pélvico, preveniria o prolapso uterino e poderia até ter as condições virginais restabelecidas. Baseado nesses argumentos, a episiotomia se tornou um procedimento rotineiro (TOMASSO et al., 2002).

Somente na década de 1980 pesquisas levantaram dúvidas em relação ao processo rotineiro da episiotomia e sua eficácia conforme preconizava DeLee, ensaios clínicos randomizados e controlados evidenciaram fatos contrários aos dele (DINIZ; CHACHAM, 2006).

Thacker e Banta publicaram em 1983 uma revisão que na época teve pouco impacto na comunidade científica, mas que demonstrava a inexistência da eficácia da episiotomia, bem como os riscos associados a ela, tais como edema, dor, infecção, hematoma e dispareunia. Dessa revisão, surgiram interesses em estudar a episiotomia, o que desencadeou no maior ensaio clínico randomizado bem controlado, um estudo argentino publicado em 1993 (OMS, 1996; BRASIL, 2001; DANNECKER et al., 2004).

A prática da episiotomia de forma rotineira varia de acordo com algumas regióes, mas é elevada a prevalência desse procedimento apesar das dúvidas e questionamentos sobre sua validade. Para o Ministério da Saúde do Brasil, a episiotomia é recomendada como uso seletivo. Estimativas apontam que entre $10 \%$ a $30 \%$ dos partos vaginais estariam em uma frequência ótima para esse uso (BRASIL, 2001).

A mulher deve decidir sobre qual procedimento será realizado no seu corpo, entendendo que a episiotomia pode ser evitada e recusada, para que não aconteça de forma desnecessária (DINIZ; CHACHAM, 2006). Ainda, destaca-se que a episiotomia pode ser considerada "violência obstétrica" (VO), que é um termo utilizado para descrever diversas formas de violência durante o cuidado obstétrico profissional, incluindo maus tratos físicos, psicológicos, verbais e procedimentos desnecessários e danosos, como as episiotomias (TESSER et al., 2015).

Alguns estudos apontam a episiotomia de rotina como uma forma de mutilação genital cometida pelas instituições de saúde e profissionais. Seu uso abusivo na área da saúde tem-se tornado uma forma de desrespeito aos direitos humanos, pois muitas mulheres desconhecem o uso da episiotomia como uma forma seletiva e não obrigatória (BRASIL, 2001). Desta forma, o presente estudo teve como objetivo mapear as percepções das parturientes em relação à episiotomia sofrida com, ou sem, seu conhecimento e consentimento e suas consequências no pós-parto.

\section{METODOLOGIA}

Tratou-se de uma pesquisa do tipo descritiva qualitativa. Este tipo de pesquisa caracteriza-se pela interpretação do conhecimento de um determinado grupo, considerando suas percepções sobre um determinado fenômeno (ROSÁRIO et al., 2013; TABORDA et al., 2014). 
A coleta de dados foi realizada em um Centro Médico Hospitalar de referência, na cidade de Campo Largo, Estado do Paraná. Participaram do estudo 50 parturientes multigestas. Foram utilizados como critérios de inclusão: parturientes multigestas com idade igual ou superior a 18 anos e que concordaram e assinaram o Termo de Consentimento Livre e Esclarecido. As parturientes foram selecionadas no acompanhamento pré parto da Instituição por nova gestação. Foram excluídas do estudo parturientes que não foram submetidas à episiotomia no parto normal.

Utilizou-se para a coleta de dados uma entrevista semiestruturada, contendo sete questões voltadas ao grau de conhecimento e orientação antecipada sobre a episiotomia, possíveis complicações e cuidados após a episiotomia, reação emocional e sobre as ações da equipe de saúde frente ao procedimento.

A entrevista foi realizada em uma sala previamente destinada para isso, sem causar desconforto à parturiente. Não houve nenhuma interferência do entrevistador nas respostas durante a entrevista, que foi gravada em áudio e transcrita para posterior avaliação pelo método de análise de conteúdo de Laurence Bardin (BARDIN, 2009). Esse modelo é determinado como um conjunto de técnicas de análise das comunicações, visando obter, por procedimentos sistemáticos e objetivos de descrição do conteúdo das mensagens, indicadores (quantitativos ou não) que permitam a inferência de conhecimentos relativos às condições de produção/recepção (variáveis inferidas) destas mensagens (BARDIN, 2009; TEILO et al., 2014).

No momento da transferência das informações as parturientes tiveram sua identidade preservada, sendo utilizado para tal identificação o uso da letra $P$ seguida de números arábicos sequenciais $\left(\mathrm{P}_{1 ;} \mathrm{P}_{2 ;} \ldots\right)$ permitindo assim, o anonimato das mesmas, atendendo as Diretrizes e Normas Regulamentadoras de Pesquisa Envolvendo Seres Humanos, por meio da resolução 466/2012 do Conselho Nacional de Saúde.

A pesquisa foi aprovada pelo Comitê de Ética em Pesquisa do Centro Universitário Campos de Andrade sob parecer consubstanciado número 1.295.309 de 2015 e autorizado pela Instituição de Saúde participante.

\section{RESULTADOS E DISCUSSÃO}

A idade das entrevistadas variou entre 18 a 40 anos, predominado entre 18 a 25 anos (52\%; $n=26)$. Algumas apresentaram problemas de saúde durante a gestação, sendo $16 \%(n=8)$ diabetes gestacional e $20 \%$ $(n=10)$ hipertensão arterial. Relativo a estes problemas $36 \%(n=18)$ foram consideradas como gestação de risco. A Tabela 1 apresenta as demais variáveis relativas a idade e tipo de parto.

Tabela 1. Classificação das parturientes quanto à idade e tipo de parto, Campo Largo, Brasil, 2015

\begin{tabular}{lcc}
\hline Variáveis & n & $\%$ \\
\hline Partos normais de 18 a 25 anos & 26 & 52 \\
$\begin{array}{l}\text { Partos normais com cesáreas posteriores de } 26 \text { a } \\
40 \text { anos }\end{array}$ & 18 & 36 \\
Somente parto cesárea & 06 & 12 \\
\hline
\end{tabular}

Das 50 parturientes entrevistadas, somaramse 85 partos normais, sendo que em $69,40 \%(n=59)$ com a realização de episiotomia. Deste total, $76,27 \%$ $(\mathrm{n}=45)$ foram realizadas sem o consentimento ou o conhecimento da parturiente. As demais variáveis são apresentadas na Tabela 2 .

Tabela 2. Episiotomias realizadas, Campo Largo, Brasil, 2015

\begin{tabular}{lcc}
\hline Variáveis & n & \% \\
\hline Partos normais com Episiotomia & 59 & 69,40 \\
$\begin{array}{l}\text { Episiotomia sem o consentimento ou } \\
\text { conhecimento }\end{array}$ & 45 & 76,27 \\
Episiotomia para auxílio no parto & 06 & 10,16 \\
Aceitas e autorizadas verbalmente & 08 & 13,55 \\
\hline
\end{tabular}

Fonte: Dados da pesquisa

Os percentuais apresentados na Tabela 2 estão bem acima dos sugeridos pelo Ministério da Saúde do Brasil, nos quais a episiotomia deveria ser recomendada apenas em situações específicas, com estimativa de recomendação para uma faixa de $10 \%$ a $30 \%$ dos partos vaginais (BRASIL, 2001).

Durante a entrevista foram abordados fatores como: grau de conhecimento e de orientação antecipada sobre o procedimento; possíveis complicações e cuidados após o mesmo; reação emocional e equipe de saúde 
frente a tal situação. Os discursos referentes a cada tópico de questionamento são apresentados a seguir.

\subsection{GRAU DE CONHECIMENTO E DE ORIENTAÇÃO ANTECIPADA SOBRE O PROCEDIMENTO}

Sobre o grau de conhecimento e de orientação sobre o procedimento, as parturientes manifestaram que a episiotomia não é algo citado pelo médico ou pela equipe de saúde como método opcional, bem como não é apresentada adequadamente antes de efetuá-lo. Os discursos abaixo ilustram esta afirmação.

Eu só escutei o médico falando para a moça do lado que ele ia cortar, porque estava com pressa, no momento não entendi, ele se quer me perguntou se poderia fazer aquilo $\mathrm{e}$ o porquê iria fazer (Paciente 07 ).

Eu não entendi nada quando ele disse "vou fazer episio" para a enfermeira, só senti a dor de um corte ardido, e logo após ele falando que tinha feito reto pra ficar mais fácil de costurar (Paciente 15).

O médico conversava com a enfermeira sobre essa tal de episiotomia, eu achei que fosse alguma doença, eles não me explicaram o que era, pensei que fosse algo com meu bebê e fiquei bem assustada. Quando foi retirar meu bebê ele disse não vai ter episio, me senti aliviada mesmo sem entender do que ele estava falando (Paciente 17).

A falta de conhecimento e consentimento sobre a episiotomia por parte da parturiente torna o procedimento uma forma de mutilação genital feminina, agredindo não só a integridade pessoal, como também a autonomia enquanto mulher. $\mathrm{O}$ corte na região genital as deixa intimidadas frente a seu cônjuge ou parceiro sexual. A grande maioria se sentiu violada e impotente para manter relações. Previamente ao procedimento deveria ocorrer a orientação pelos profissionais dos serviços de saúde, entendendo que mulheres são seres humanos com capacidade de decisão, dotadas de emoções e discernimento (PROGIANTI; ARAÚJO; MOUTA, 2008).

Conforme relatado pela maioria das mulheres, não houve alguma orientação antecipada sobre $o$ procedimento, seja no momento do parto ou no pré-natal. Portanto, considera-se a episiotomia um procedimento que viola os direitos reprodutivos e sexuais da mulher, desrespeitando os princípios éticos profissionais. De acordo com médicos e enfermeiras obstétricas é a única operação feita sobre o corpo de uma mulher saudável sem seu consentimento (DINIZ, 2001).

Outro fato se deve ao consentimento prévio, que caso não ocorra, considera-se a episiotomia como violência obstétrica, a qual se caracteriza por qualquer ato exercido por profissionais da saúde no que cerne o corpo e aos processos reprodutivos das mulheres, exprimindo por meio de uma atenção desumanizada, abuso de ações intervencionistas, medicalização e a transformação patológica dos processos de parturição fisiológicos (ZVEITER; PROGIANTI; VARGENS, 2005).

Dentro deste contexto, são responsabilidades e deveres dos profissionais de enfermagem, de acordo com a Resolução número 311/2007 do Conselho Federal de Enfermagem Art. 18, respeitar, reconhecer e realizar ações que garantam o direito da pessoa ou de seu representante legal, de tomar decisões sobre sua saúde, tratamento, conforto e bem estar. Ainda, o Art. 21 cita proteger a pessoa, família e coletividade contra danos decorrentes de imperícia, negligência ou imprudência por parte de qualquer membro da equipe de saúde (Conselho Federal de Enfermagem (COFEN). Decreto $\mathrm{N}^{\circ}$ 94.406/87. Regulamenta a Lei $\mathrm{n}^{\circ} \mathbf{7 . 4 9 8}$, de 25 de junho de 1986, que dispõe sobre o exercício da Enfermagem, e dá outras providências).

Em um estudo desenvolvido por Santos e Shimo (SANTOS; SHIMO, 2008) que teve por objetivo avaliar o conhecimento e participação de parturientes sobre a realização da episiotomia, foi possível identificar que as mulheres não conhecem o procedimento $\mathrm{e}$ que a episiotomia foi realizada sem informação e sem autorização das mesmas. Desta forma, fica evidente que o profissional assume todo o controle das decisões sem discutir previamente com suas pacientes (OLIVEIRA et al., 2016). 


\subsection{POSSÍVEIS COMPLICAÇÕES E CUIDADOS APÓS A EPISIOTOMIA}

Algumas das parturientes relataram que a episiotomia foi uma forma de mutilação genital, ocasionando sérias complicações e desencadeando até em perda do prazer sexual, incontinência urinária e ligamento da vagina ao ânus. Os cuidados que deveriam ser tomados após o parto não foram devidamente explicados, o que em algumas mulheres desencadeou infecção local, como descrevem os discursos abaixo.

\begin{abstract}
Ele fez um corte na minha vagina que chegou a encostar ao ânus, costurou de qualquer forma, ficando uns pedaços de carne pra fora, fez tipo uns gominhos. Quando eu ia fazer cocô, sujava todos os pontos, ai acabou infeccionando e demorou muito pra cicatrizar (Paciente 2).

Depois que o médico me cortou, eu não consigo mais ter o mesmo prazer na relação com meu marido, ele diz que minha vagina ficou estragada (Paciente 33).
\end{abstract}

Muitas mulheres descreveram a sensação horrível que as submeteram, realizando muitas vezes o corte sem anestesia e realizando a episiorrafia de qualquer forma. Deste modo, a episiotomia se tornou além de uma experiência dolorosa, um trauma, pois no momento de sua realização a mulher é incapaz de reagir a tal intervenção externa (ZVEITER; PROGIANTI; VARGENS, 2005). Neste sentido, dados de uma pesquisa nacional enumeraram o problema apontando que cerca de $1 / 4$ das mulheres que tinham parido, e também aproximadamente metade das que abortaram, relataram alguma forma de violência obstétrica (VENTURI; GODINHO, 2013).

A dor sofrida no processo de parto torna-se muitas vezes inesquecível para algumas parturientes, o que pode impedir que as mesmas voltem a ter o desejo de engravidar. Neste estudo foi perceptível que a dor advinda da episiotomia, deixou sequelas não só físicas como emocionais. Dentre as sequelas físicas, a episotomia aumenta o risco de laceração perineal de terceiro e quarto graus, de infecção e de hemorragia, sem diminuir complicações a longo prazo de dor e incontinência urinária e fecal (RÄISÄNEN et al, 2011; TESSER et al., 2015).

\subsection{REAÇÃO EMOCIONAL}

As parturientes demonstraram sentimento de revolta e descaso com sua particularidade. A falta de compreensão e respeito para com seu momento de mãe e mulher trouxe a elas o descontentamento com o dia do nascimento de seu filho, conforme explicito nos relatos:

Eu me senti a pior mulher do mundo, quando o médico me cortou sem me perguntar o que eu achava, como se eu não estivesse ali, como se eu fosse um boneco (Paciente $50)$.

Tudo ardia, fui agredida da pior maneira, como mãe e como mulher, nem pensou como seria depois que meu filho nascesse, se minha vagina seria a mesma ou não, simplesmente cortou (Paciente 22).

Ele apenas disse assim, vou fazer um cortinho pra ajudar teu filho a sair, mas eu já tive 3 filhos, como assim cortinho? Não precisava de corte nenhum, os outros não precisaram por que esse precisava? Fez sem anestesia, doeu demais, mais que a própria dor de parto (Paciente 10).

Indiscutivelmente o parto é um momento importante na vida de uma mulher, obviamente que quando a mesma é tratada com respeito e dignidade para que possa ter lembranças de um parto humanizado e o mais natural possível. Na maioria das vezes o parto não precisa de muito para acontecer, pois é um fenômeno fisiológico, e esperado para acontecer naturalmente.

Nestes termos, a episiotomia pode ser considerada uma violação dos direitos sexuais e reprodutivos da mulher. Muitas referem dispareunia e se sentem preocupadas em relação a deformidades na genitália. Portanto, o profissional de saúde deve colocar o respeito ao corpo e bem estar da mulher em evidência, reduzindo os prejuízos físicos, fisiológicos, emocionais e psicológicos serão diminuídos ao máximo (OLIVEIRA et al., 2016).

\subsection{EQUIPE DE SAÚDE FRENTE A TAL SITUAÇÃO}

Conforme relatado pelas mulheres, a equipe de saúde, na maioria dos casos, deixou a desejar e não orientou as parturientes quanto ao procedimento 
que poderia ser realizado. As mesmas evidenciaram que médicos ou enfermeiros não tiveram a atenção de explicar sobre a episiotomia, se ela poderia acontecer e em quais casos seria necessária, conforme os discursos a seguir.

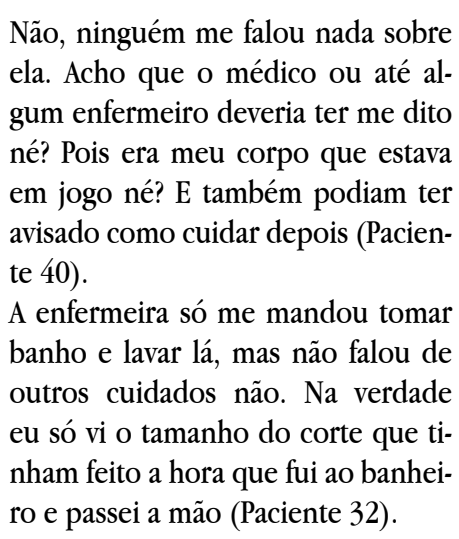

Destaca-se que no Brasil, a quase totalidade dos partos é realizada em instituições hospitalares. Desta forma, a assistência ao parto realizada por profissionais capacitados é o fator mais importante para diminuição da mortalidade materna e complicações decorrentes. Ainda, apesar da elevada cobertura de pré-natal $(98,7 \%)$ no Brasil, apenas $40 \%$ das mulheres afirma ter recebido orientações sobre práticas benéficas para o trabalho de parto (TESSER et al., 2015).

Neste sentido, deve ser prática do profissional de saúde acolher a mulher e identificar suas necessidades de forma individualizada, ofertando atendimento de qualidade e humanizado. Ressalta-se ainda, que devem ser baseados em princípios éticos e com o uso de procedimentos que tragam benefícios evitando intervenções desnecessárias e que garanta a autonomia e a privacidade, compartilhando as condutas a serem adotadas com a mulher e sua família (OLIVEIRA et al., 2016).

\section{CONCLUSÃO}

Por meio das análises dos depoimentos foi possível evidenciar as várias percepções e opiniões das parturientes durante a realização da episiotomia. Observou-se uma notória insatisfação das entrevistadas enquanto pacientes. As falas sugerem que a realização da episiotomia representou uma violação dos direitos sexuais, reprodutivos e emocionais das mesmas. Por fim, o estudo deixa claro que a episiotomia é um procedimento pouco conhecido e evidenciado pelos profissionais de saúde às pacientes. Tanto os médicos como os enfermeiros, particularmente citados, não tiveram a atenção de apresentar a episiotomia às pacientes, como um dos procedimentos possíveis durante o parto, explicando sobre seus riscos e benefícios e em quais casos seria necessária a sua realização.

\section{REFERÊNCIAS}

BARDIN, L. Análise de conteúdo. Edições 70, Lisboa, 2009. ISBN 9724400204.

BRASIL. Ministério da Saúde. Secretaria de Políticas de Saúde. Área Técnica de Saúde da Mulher. Parto, aborto e puerpério: assistência humanizada à mulher. Brasília: Ministério da Saúde, 2001.

CONSELHO FEDERAL DE ENFERMAGEM - COFEN. Decreto $\mathrm{N}^{\circ}$ 94.406/87. Regulamenta a Lei $\mathrm{n}^{\circ} 7.498$, de 25 de junho de 1986, que dispõe sobre o exercício da Enfermagem, e dá outras providências. Disponível em: $<$ http://www.cofen.gov.br/decreto-n-9440687_4173. html >. Acesso em: 02 nov. 2014.

DANNECKER, C. et al. Episiotomy and perineal tears presumed to be imminent: randomized controlled trial. Acta obstet gynecol scand suppl, v. 83, n. 4, p. 364$368,2004$.

DINIZ, C. S. G. Entre a técnica e os direitos humanos: possibilidades e limites da humanização da assistência ao parto. 2001. Tese (Doutorado em Medicina) Universidade de São Paulo, São Paulo.

DINIZ, S. G.; CHACHAM, A. S. O "corte por cima" e o "corte por baixo": o abuso de cesáreas e episiotomias em São Paulo. Questões de Saúde Reprodutiva, v. 1, n. 1, p. 80-91, 2006.

OLIVEIRA, A. P. G. et al. Episiotomia: discussão sobre o trauma psicológico e físico nas puérperas: uma revisão 
bibliográfica. Rev Rede de Cuidados em Saúde, v. 10, n. 1, p. 1-13, 2016.

OMS. Organização Mundial da Saúde (OMS). Assistência ao parto normal: um guia prático. Brasilia: OMS, 1996.

PROGIANTI, J. M.; ARAÚJO, L. M.; MOUTA, R. J. O. Repercussões da episiotomia sobre a sexualidade. Esc Anna Nery Rev Enferm, v. 12, n. 1, p. 45-9, 2008.

RÄISÄNEN, S. et al. A population-based register study to determine indications for episiotomy in Finland. Int $\mathbf{J}$ Gynaecol Obstet, v. 115, n. 1, p. 26-30, 2011.

ROSÁRIO, E. N. et al. Family refusal facing a potential organ donor. Cad Saude Colet., v. 21, n. 3, p. 260-266, 2013.

SANTOS, J. O.; SHIMO, A. K. K. Prática rotineira da episiotomia refletindo a desigualdade de poder entre profissionais de saúde e mulheres. Esc Anna Nery Rev Enferm, v. 12, n. 4, p. 645-650, 2008.

TABORDA, J. A. et al. Consequências da gravidez na adolescência para as meninas considerando-se as diferenças socioeconômicas entre elas. Cad. Saúde Colet., v. 22, n. 1, p. 16-24, 2014.

TEILO, M. A. et al. Fatores relacionados à adesão do exame colpocitopatólogico no munícipio de Cerro Azul. Cienc Cuid Saude, v. 13, n. 1, p. 90-96, 2014.

TESSER, C. D. et al. Violência obstétrica e prevenção quaternária: o que é e o que fazer. RBMFC, v. 10, n. 35, p. 1-12, 2015.

TOMASSO, G. et al. Debemos seguir haciendo la episiotomía en forma rutinaria? Rev. obstet. ginecol. Venezuela, v. 62, n. 2, p. 115-121, 2002.

TORTORA, G. J.; DERRICKSON, B. Corpo humano: fundamentos de anatomia e fisiologia. [s.l.]: Artmed, 2012.

VENTURI, G.; GODINHO, T. Mulheres brasileiras e gênero nos espaços público e privado: uma década de mudanças na opinião pública. São Paulo: Fundação Perseu Abramo/SESC-SP, 2013.
ZVEITER, M.; PROGIANTI, J. M.; VARGENS, O. M. C. O trauma no parto e nascimento sob a lente da enfermagem obstétrica. Pulsional Rev Psicanál, v. 182, n. 6, p. 86-92, 2005.

Recebido em: 30 de setembro de 2016 Aceito em: 01 de março de 2017 